\title{
Polyvinylpolypyrrolidone Supported Brønsted Acidic Catalyst for Esterification
}

\author{
Song Wang and Chengcheng Tian \\ School of Science, Shenyang University of Technology, Shenyang 110870, China \\ Correspondence should be addressed to Song Wang; 1259669134@qq.com
}

Received 16 August 2016; Revised 21 October 2016; Accepted 2 November 2016

Academic Editor: Akshat Tanksale

Copyright (C) 2016 S. Wang and C. Tian. This is an open access article distributed under the Creative Commons Attribution License, which permits unrestricted use, distribution, and reproduction in any medium, provided the original work is properly cited.

\begin{abstract}
A polyvinylpolypyrrolidone (PVPP) supported Brønsted acidic catalyst ([PVPP-BS] $\mathrm{HSO}_{4}$ ) was prepared by coupling $\mathrm{SO}_{3} \mathrm{H}-$ functionalized polyvinylpolypyrrolidone with $\mathrm{H}_{2} \mathrm{SO}_{4}$ in this work. After the characterization through FT-IR, FESEM, TG, BET, and elemental analysis, it was found that 1,4-butane sultone (BS) and sulfuric acid reacted with PVPP and were immobilized on PVPP surface. The prepared [PVPP-BS] $\mathrm{HSO}_{4}$ catalyst shows high catalytic activity for a series of esterification reactions and could be separated from the reacted mixture easily. Moreover, this catalyst could be recycled and reused for six times without significant loss of catalytic performance.
\end{abstract}

\section{Introduction}

Esters have been widely used as lubricating oils, perfumes, plasticizers, biodegradable materials, and so forth $[1,2]$. Conventionally, esterification could be catalyzed by mineral acids such as $\mathrm{H}_{2} \mathrm{SO}_{4}$ and $\mathrm{H}_{3} \mathrm{PO}_{4}$. However, these acids were reported to exhibit several drawbacks including severe corrosion to equipment, environmental hazards, and difficulty in the aspect of catalyst reusability [3]. To overcome these problems, heterogeneous solid acid catalysts such as supported mineral acids, acidic resins, and zeolites were developed [4]. Nevertheless, these heterogeneous catalysts were illustrated to exhibit some disadvantages related to product selectivity, catalyst recyclability, and environmental safety [5]. As such, developing high catalytic activity, recyclable, environmentalfriendly catalysts for esterification is still an attractive topic in catalyst field [6].

Owing to the negligible selective dissolvability and tunable acidity, ILs (ionic liquids) were utilized as environmentalfriendly solvents and catalysts for chemical reactions [710]. Many organic reactions were catalyzed by ILs which were revealed to be promising catalysts for esterification and transesterification. Gui et al. [11] employed three halogenfree Brønsted acidic ionic liquids as catalysts for esterification of ethanol with acetic acid. They illustrated that these ILs were effective catalysts for esterification with the conversion rate of ethanol higher than $92 \%$. Nevertheless, ILs were demonstrated to have some disadvantages such as high viscosity, inconvenient reusability, and large amount needed in reaction $[12,13]$.

In recent years, polymer supported catalysts were developed, which had advantages in product purification, reducing environmental damage, and easy separation from product. These exhibited characteristics made polymer supported catalysts promising for both academic and industrial applications [14-17]. Leng et al. [18] prepared a polymer supported acidic catalyst by coupling a polymeric IL with heteropolyanions, and their findings showed that when this catalyst was used in the esterification of acetic acid with n-butanol, a conversion rate of n-butanol higher than $97 \%$ was obtained. However, due to the complex preparation and polymerization of the monomer, the whole preparation process of polymer supported acidic catalysts is always complicate and less satisfactory.

Polyvinylpolypyrrolidone [PVPP] is a commercial product usually used as adsorbent $[19,20]$. Recently, its application in catalyst field has drawn much attention because it has many advantages such as being insoluble in all kinds of solvents 


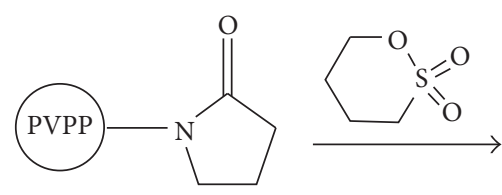

PVPP

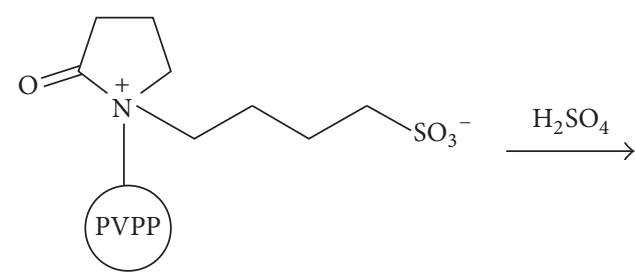

PVPP-BS

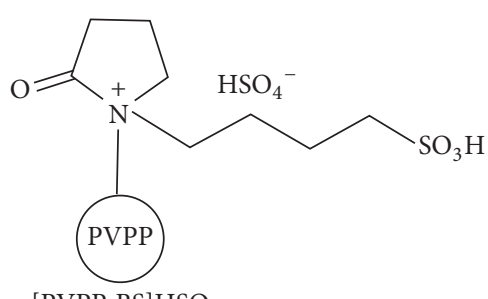

$[\mathrm{PVPP}-\mathrm{BS}] \mathrm{HSO}_{4}$

SCHEMe 1: Synthesis of [PVPP-BS] $\mathrm{HSO}_{4}$.

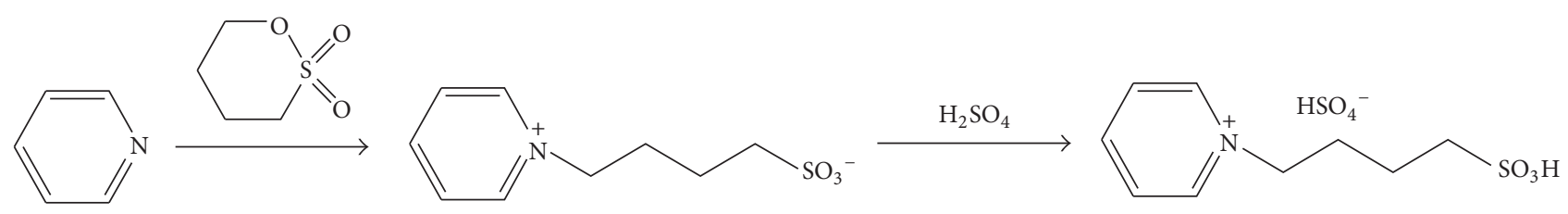

SCHeme 2: Synthesis of [BSPy] $\mathrm{HSO}_{4}$.

and nontoxic. Mokhtary and Najafizadeh [21] used PVPP supported boron trifluoride as the catalyst to prepare N-tertbutyl amides by reaction of nitriles with tert-butyl acetate. They found that PVPP supported boron trifluoride was a high efficient Lewis acid. In this study, a commercial PVPP was applied to synthesize a Brønsted acidic catalyst. The catalytic activity and reusability performance of this catalyst used for esterification reactions were also investigated.

\section{Experimental Part}

2.1. Materials. PVPP was provided by Gobekie New Materials Science \& Technology Co., Ltd, Shanghai, China. 1,4Butane sultone (BS) (99\%), sulfuric acid (98\%), and other chemicals (AR grade) were purchased from Sinopharm Chemical Reagent Co. and used as received.

2.2. Preparation of $[\mathrm{PVPP}-\mathrm{BS}] \mathrm{HSO}_{4}, \mathrm{PVPP}_{-} \mathrm{H}_{2} \mathrm{SO}_{4}$, and 1-(4Sulfonic acid) Butylpyridinium Hydrogen Sulfate ([BSPy] $\mathrm{HSO}_{4}$ ). All experimental steps were carried out under nitrogen atmosphere. First, [PVPP-BS] $\mathrm{HSO}_{4}$ was prepared in the following steps. Under vigorous stirring, PVPP powder $(10 \mathrm{~g}$, monomer molar quantity was about $0.09 \mathrm{~mol}$ ) was dispersed in toluene and then an appropriate amount of BS (ranging from 0 to $0.09 \mathrm{~mol}$ ) was added to the mixture. The mixture was slowly heated to $80^{\circ} \mathrm{C}$ and continuously stirred in a $250 \mathrm{~mL}$ round-bottomed flask for $24 \mathrm{~h}$. After filtration, the zwitterions powder (PVPP-BS) was washed three times with ethyl acetate and then dried in vacuum at $60^{\circ} \mathrm{C}$ to obtain PVPP-BS. Then, sulfuric acid (ranging from 0 to $0.09 \mathrm{~mol}$ ) in equimolar amount to BS was added to the mixture of PVPPBS dispersed in methanol at $0^{\circ} \mathrm{C}$ and stirred for $24 \mathrm{~h}$. On completion, the mixture was filtered and washed three times with methanol, and then water and methanol were removed in vacuum at $60^{\circ} \mathrm{C}$ to afford the final product [PVPPBS] $\mathrm{HSO}_{4}$ as a solid. The preparation process of [PVPPBS] $\mathrm{HSO}_{4}$ is shown in Scheme 1.

For comparison, two other catalysts $\mathrm{PVPP}-\mathrm{H}_{2} \mathrm{SO}_{4}$ and 1-(4-sulfonic acid) butylpyridinium hydrogen sulfate
([BSPy] $\mathrm{HSO}_{4}$ ) were also prepared. The preparation procedure of PVPP- $\mathrm{H}_{2} \mathrm{SO}_{4}$ was as follows. PVPP powder $(10 \mathrm{~g})$ was dispersed in ethyl acetate and then sulfuric acid $(0.09 \mathrm{~mol})$ was added to the mixture at $0^{\circ} \mathrm{C}$ and stirred for $24 \mathrm{~h}$. On completion, the mixture was filtered and washed three times with methanol. Then, water and methanol were removed in vacuum at $60^{\circ} \mathrm{C}$ to afford the final product of PVPP- $\mathrm{H}_{2} \mathrm{SO}_{4}$ as a solid.

[BSPy] $\mathrm{HSO}_{4}$ was synthesized as reported in the previous literature with a slight modification [22]. Pyridine (0.11 mol) and 1,4-butane sultone $(0.1 \mathrm{~mol})$ were introduced into a $100 \mathrm{~mL}$ capacity round-bottom flask reactor equipped with a reflux condenser, a magnetic stirrer, and a thermometer. This reaction system was stirred magnetically under reflux at $40^{\circ} \mathrm{C}$ for $24 \mathrm{~h}$ until a white solid zwitterion (BSPy) formed, which was filtered, washed with ethyl acetate three times to remove nonionic residues, and dried in vacuum. Sulfuric acid $(0.1 \mathrm{~mol})$ was added dropwise and the mixture was stirred at $80^{\circ} \mathrm{C}$ for $8 \mathrm{~h}$. The obtained viscous liquid was washed with ether for three times and dried in vacuum to form ionic liquid [BSPy] $\mathrm{HSO}_{4}$. The preparation process of [BSPy] $\mathrm{HSO}_{4}$ is shown in Scheme 2.

2.3. Catalyst Characterization. FT-IR spectra were measured on a PRESTIGE-21 FT-IR instrument ( $\mathrm{KBr}$ discs) in the $2200-400 \mathrm{~cm}^{-1}$ region. Thermal analysis was performed with a TA Q50 thermogravimetric analyzer in a nitrogen atmosphere with a heating rate of $10^{\circ} \mathrm{C} / \mathrm{min}$. The surface morphologies of PVPP, PVPP-BS, and [PVPP-BS] $\mathrm{HSO}_{4}$ were investigated by using a Hitachi SU8000 field emission scanning electron microscopy (FESEM). Elemental analysis was performed on an Elementar Vario EL Cube elemental analyzer. The BET surface area was measured at the liquidnitrogen temperature using a Micromeritics SSA4200 analyzer. Before the BET surface area analysis, the samples were degassed at $100^{\circ} \mathrm{C}$ to the vacuum of $0.13 \mathrm{~Pa}$. The multipoint Brunauer-Emmett-Teller (BET) method was used to measure total surface area. The acid value of [PVPP-BS] $\mathrm{HSO}_{4}$ was determined by acid-base titration $[23,24]$. One-half gram of 
the catalyst powder was dispersed in $50 \mathrm{~mL}$ of $0.1 \mathrm{M} \mathrm{KCl}$. The dispersion was stirred for $20 \mathrm{~min}$ and titrated with $0.1 \mathrm{M} \mathrm{KOH}$ in the presence of phenolphthalein.

2.4. Esterification and Analysis. Taking the esterification of acetic acid with $n$-butanol as an example, the typical reaction was carried out as follows: acetic acid $(0.08 \mathrm{~mol})$, n-butanol (0.096 mol), cyclohexane ( $8 \mathrm{~mL}$, as a water-carrying agent), and [PVPP-BS] $\mathrm{HSO}_{4}(1.19 \mathrm{~g}, 8 \%$ of the total mass of $\mathrm{n}$ butanol and acetic acid) were introduced into a $100 \mathrm{~mL}$ capacity round-bottom flask reactor equipped with a water segregator, thermometer, reflux condenser, and magnetic stirrer. The mixture was heated under reflux at $90^{\circ} \mathrm{C}$ with vigorous stirring for $3 \mathrm{~h}$. After the reaction completed, the product was analyzed by a gas chromatograph (GC) instrument with FID detector (Agilent 7890 A, HP 5 capillary column $30 \mathrm{~m} \times 0.32 \mathrm{~mm} \times 0.25 \mu \mathrm{m})$. Other esterification reactions were carried out in the same procedure. The conversion of the carboxylic acid and the selectivity of esters were determined as described in previous literatures $[18,25]$.

2.5. Recycling of Catalysts. The catalyst [PVPP-BS] $\mathrm{HSO}_{4}$ was recovered by vacuum filtration and dried in vacuum at $60^{\circ} \mathrm{C}$ for $2 \mathrm{~h}$. This recovered catalyst was directly used for the next run.

\section{Results and Discussion}

3.1. Effect of the Ratio of BS to the Pyrrolidone Repeat Unit of PVPP on the Catalytic Activity. BS can only react with the pyrrolidone repeat unit exposed on the surface of PVPP because PVPP is a cross-linking insoluble material. However, due to the lack of reliable method to measure the amount of the pyrrolidone repeat unit exposed on the surface of PVPP, the ratio of BS to the pyrrolidone repeat unit of PVPP, which can greatly affect the catalytic performance of the catalyst, cannot be calculated directly. Therefore, to examine the effect of the ratio of BS to the pyrrolidone repeat unit of PVPP on the catalytic activity, several catalysts synthesized with different mole ratio of BS to the pyrrolidone repeat unit of PVPP were utilized in the esterification of $n$-butanol with acetic acid. As shown in Figure 1, with the increase of mole ratio of BS to the pyrrolidone repeat unit of PVPP, a higher conversion rate of acetic acid was obtained. When the mole ratio of BS to the pyrrolidone repeat unit of PVPP was increased up to 0.5 , the achieved conversion of acetic acid was about $99.6 \%$. With the mole ratio of BS to the pyrrolidone repeat unit of PVPP increased continually, the conversion did not change significantly. This result indicates that the satisfied ratio of BS to the pyrrolidone repeat unit of PVPP is 0.5 .

\subsection{Catalyst Characterization}

3.2.1. FT-IR Spectroscopy. The FT-IR spectra results of PVPP, PVPP-BS, [PVPP-BS] $\mathrm{HSO}_{4}$, and $\mathrm{H}_{2} \mathrm{SO}_{4}$ are presented in Figure 2. The characteristic peaks around $1290 \mathrm{~cm}^{-1}$, $1438 \mathrm{~cm}^{-1}$, and $1654 \mathrm{~cm}^{-1}$ which could be clearly observed in Figure 2 were assigned to $\mathrm{C}-\mathrm{N}, \mathrm{C}-\mathrm{C}$, and $\mathrm{C}=\mathrm{O}$ stretching

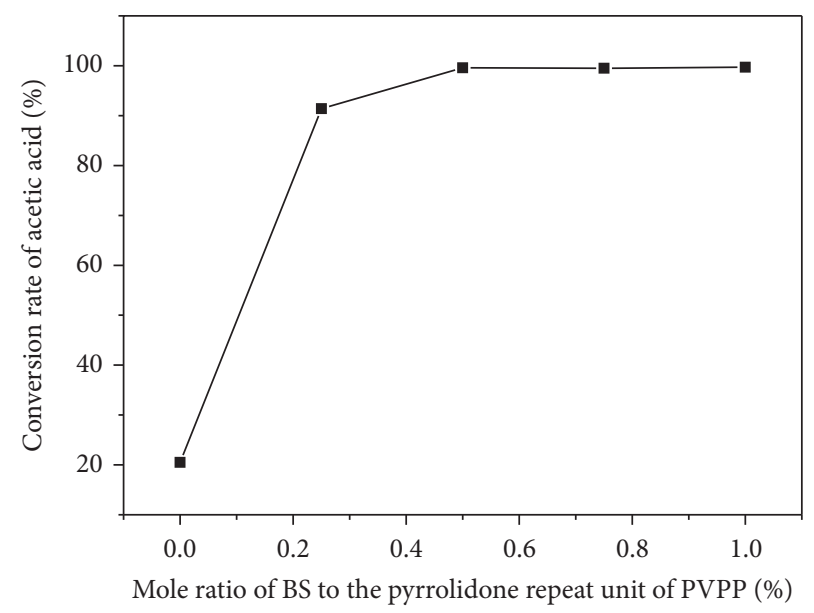

FIGURE 1: Conversion of acetic acid catalyzed by [PVPP-BS] $\mathrm{HSO}_{4}$ catalysts synthesized with different mole ratios of BS to the pyrrolidone repeat unit of PVPP. (Reaction conditions: n-butanol $96 \mathrm{mmol}$, acetic acid $80 \mathrm{mmol}$, [PVPP-BS] $\mathrm{HSO}_{4}$ catalyst $8 \mathrm{wt} \%$, and $90^{\circ} \mathrm{C}$ for 3 h.)

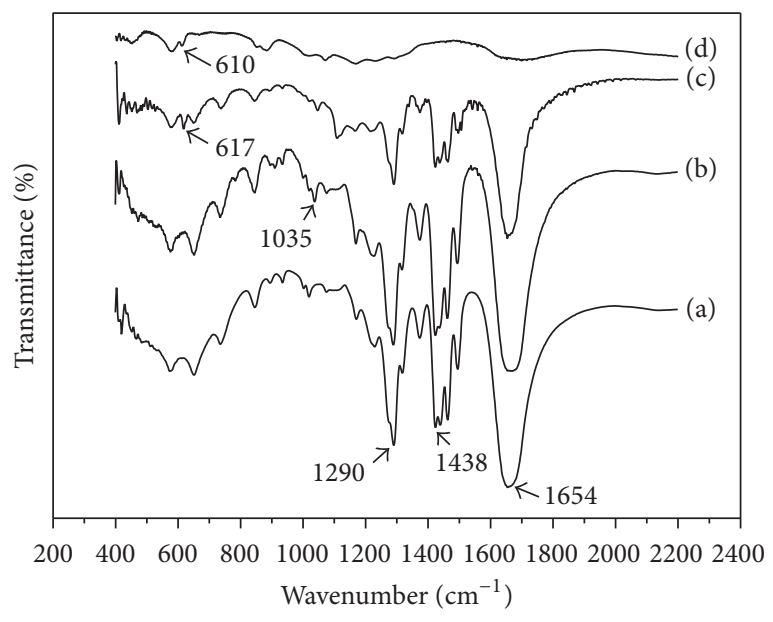

FIGURE 2: The comparative FT-IR spectra of (a) PVPP, (b) PVPP-BS, (c) [PVPP-BS] $\mathrm{HSO}_{4}$, and (d) $\mathrm{H}_{2} \mathrm{SO}_{4}$.

vibrations of PVPP, respectively [26]. The band in Figure 2(b) at $1035 \mathrm{~cm}^{-1}$, which did not appear in Figure 2(a), was attributed to the $\mathrm{S}=\mathrm{O}$ symmetric stretching vibrations as reported in a literature [22]. This result indicates that BS has been connected to the surface of PVPP. Moreover, comparing $\mathrm{H}_{2} \mathrm{SO}_{4}$ with [PVPP-BS] $\mathrm{HSO}_{4}$ in Figures 2(d) and 2(c), it can be clearly observed that after PVPP-BS reacted with $\mathrm{H}_{2} \mathrm{SO}_{4}$, the symmetric stretching vibration of $\mathrm{S}-\mathrm{O}$ band had shifted from $610 \mathrm{~cm}^{-1}$ to $617 \mathrm{~cm}^{-1}$. This is a convincing evidence of the existence of the strong ionic interaction between the polymeric cations and $\mathrm{HSO}_{4}{ }^{-}$. It thus suggests that the reaction of $\mathrm{SO}_{3} \mathrm{H}$-functionalized PVPP with $\mathrm{H}_{2} \mathrm{SO}_{4}$ produced a PVPP-based polymeric hybrid via ionic linkages.

3.2.2. Thermogravimetric Analysis. Thermal stabilities of PVPP, PVPP-BS, and [PVPP-BS] $\mathrm{HSO}_{4}$ were determined by 


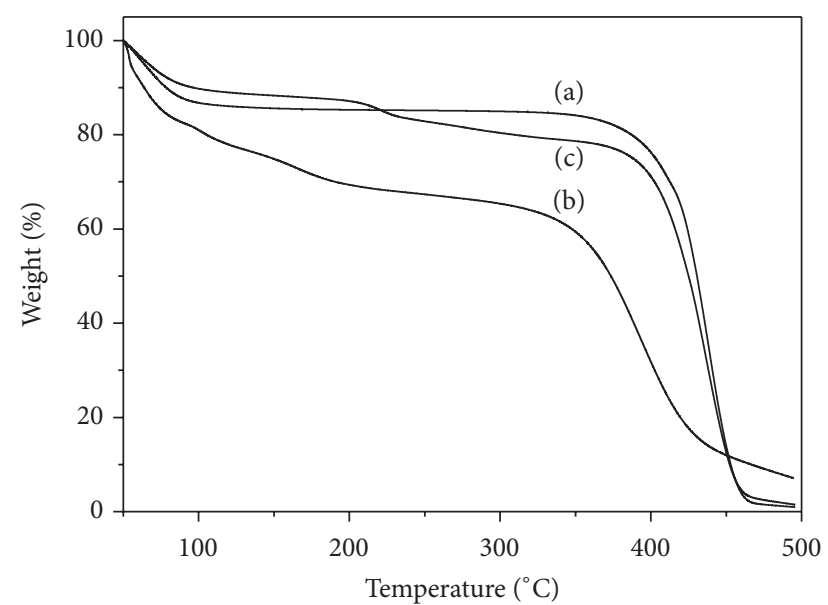

FIgURE 3: Thermogravimetric curves of (a) PVPP, (b) PVPP-BS, and (c) $[\mathrm{PVPP}-\mathrm{BS}] \mathrm{HSO}_{4}$.

TG analysis. In Figures 3(b) and 3(c), besides the drastic weight loss at temperature ranging from $350^{\circ} \mathrm{C}$ to $500^{\circ} \mathrm{C}$ corresponding to the thermal decomposition of PVPP backbone in the catalyst, there was another weight loss around $200^{\circ} \mathrm{C}$. The TG curve of PVPP-BS, curve (b) in Figure 3, shows that there was an approximately $4.5 \%$ weight loss of the sample between $150^{\circ} \mathrm{C}$ and $190^{\circ} \mathrm{C}$, while that of [PVPPBS] $\mathrm{HSO}_{4}$, curve (c) in Figure 3, exhibits that there was an approximately $3 \%$ weight loss of the sample between $200^{\circ} \mathrm{C}$ and $240^{\circ} \mathrm{C}$. The finding that $[\mathrm{PVPP}-\mathrm{BS}] \mathrm{HSO}_{4}$ had much higher decomposition temperature and less weight loss than PVPP-BS strongly indicates that [PVPP-BS] $\mathrm{HSO}_{4}$ is not a physical mixture of PVPP-BS with $\mathrm{H}_{2} \mathrm{SO}_{4}$ but an ionic hybrid.

3.2.3. Morphological Surface Analysis. Figure 4 shows the diameters and surface morphologies of (a) PVPP, (b) PVPP$\mathrm{BS}$, and (c) [PVPP-BS] $\mathrm{HSO}_{4}$. It can be clearly seen that the amorphous PVPP particles before reaction were aggregated together with size of 3-5 um (Figure 4(a)). However, after reacting with $\mathrm{BS}$ or $\mathrm{H}_{2} \mathrm{SO}_{4}$, the surface of PVPP-BS and [PVPP-BS] $\mathrm{HSO}_{4}$ was not as smooth as that of PVPP, and small particles could be seen on the surface (Figures 4(b) and $4(\mathrm{c}))$. These small particles made the BET surface area of PVPP-BS $\left(6.28 \mathrm{~m}^{2} / \mathrm{g}\right)$ and [PVPP-BS] $\mathrm{HSO}_{4}\left(6.56 \mathrm{~m}^{2} / \mathrm{g}\right)$ much higher than that of PVPP $\left(3.84 \mathrm{~m}^{2} / \mathrm{g}\right)$ (Table 1). The elemental analysis results in Table 1 demonstrate the difference in S element content in PVPP, PVPP-BS, and [PVPP$\mathrm{BS}] \mathrm{HSO}_{4}$. The sulfur content in [PVPP-BS] $\mathrm{HSO}_{4}(8.789 \%)$ was higher than that in PVPP-BS (4.121\%). In contrast, no sulfur content was found in PVPP. These findings further demonstrate that $\mathrm{BS}$ and $\mathrm{H}_{2} \mathrm{SO}_{4}$ have already reacted with PVPP.

3.3. Catalytic Activities of Different Catalysts. The catalytic performance of different catalysts for the esterification of acetic acid with $\mathrm{n}$-butanol is presented in Table 2. It can be observed that the conversion of acetic acid only reached $20.3 \%$ (entry 1 ) when catalysts were not used, which means
TABLE 1: Characterization data of PVPP, PVPP-BS, and [PVPP$\mathrm{BS}] \mathrm{HSO}_{4}$.

\begin{tabular}{lccc}
\hline Sample & S\% $^{\mathrm{a}}$ & $\begin{array}{c}\text { Acidity }^{\mathrm{b}} \\
\mathrm{mg} / \mathrm{g}\end{array}$ & BET surface area $\mathrm{m}^{2} / \mathrm{g}$ \\
\hline PVPP & - & - & 3.84 \\
PVPP-BS & 4.121 & - & 6.28 \\
${\text { PVPP-BS] } \mathrm{HSO}_{4}}$ & 8.789 & 274.89 & 6.56 \\
\hline
\end{tabular}

${ }^{\mathrm{a}}$ Weight percentage of $\mathrm{S}$ element determined by an elemental analyzer

${ }^{\mathrm{b}}$ Determined as $\mathrm{KOH}$ mass consumed for neutralization.

TABLE 2: Esterification of n-butanol and acetic acid under different conditions ${ }^{\mathrm{a}}$. $\mathrm{CH}_{3} \mathrm{COOH}+\mathrm{CH}_{3}\left(\mathrm{CH}_{2}\right)_{3} \mathrm{OH} \rightarrow \mathrm{CH}_{3} \mathrm{COO}\left(\mathrm{CH}_{2}\right)_{3} \mathrm{CH}_{3}$ $+\mathrm{H}_{2} \mathrm{O}$.

\begin{tabular}{lccc}
\hline Entry & Catal. & Conv. $(\%)^{\mathrm{b}}$ & Sel. $(\%)^{\mathrm{c}}$ \\
\hline 1 & - & 20.3 & 100 \\
2 & $\mathrm{H}_{2} \mathrm{SO}_{4}$ & 85.1 & 87.1 \\
3 & $\mathrm{PVPP}_{4} \mathrm{HO}_{4}$ & 89.3 & 88.5 \\
4 & $\mathrm{H}_{3} \mathrm{PW}_{12} \mathrm{O}_{40}$ & 96.9 & 95.8 \\
5 & {$\left[\mathrm{BSPy}_{\mathrm{HSO}}\right.$} & 96.1 & 100 \\
6 & {$\left[\mathrm{PVPP}_{4} \mathrm{BS}\right] \mathrm{HSO}_{4}$} & 99.6 & 100 \\
\hline
\end{tabular}

${ }^{a}$ n-Butanol (7.12 g); acetic acid (4.80 g); and [PVPP-BS] $\mathrm{HSO}_{4}(8 \mathrm{wt} \%), 90^{\circ} \mathrm{C}$ for $3 \mathrm{~h} . \mathrm{H}_{2} \mathrm{SO}_{4}, \mathrm{H}_{3} \mathrm{PW}_{12} \mathrm{O}_{40}$, PVPP- $\mathrm{H}_{2} \mathrm{SO}_{4}$, and [BSPy] $\mathrm{HSO}_{4}$ were used in a similar proton content as [PVPP-BS] $\mathrm{HSO}_{4}$.

${ }^{\mathrm{b}}$ Conversion of acetic acid.

${ }^{\mathrm{c}}$ Selectivity for ester.

that the esterification was difficult to occur with the absence of catalysts. When $\mathrm{H}_{2} \mathrm{SO}_{4}$ was used as the catalyst in the esterification, a homogeneous reaction system was formed and $\mathrm{H}_{2} \mathrm{SO}_{4}$ exhibited a low conversion of $85.1 \%$ and selectivity of $87.1 \%$ (entry 2). This homogeneous reaction system made it difficult to separate $\mathrm{H}_{2} \mathrm{SO}_{4}$ from the product. Although PVPP- $\mathrm{H}_{2} \mathrm{SO}_{4}$ is a heterogeneous catalyst which is easy to prepare, when used as the catalyst in esterification, it exhibited the similar catalytic ability as $\mathrm{H}_{2} \mathrm{SO}_{4}$, and the low conversion of $89.3 \%$ and selectivity of $88.5 \%$ were obtained (entry 3 ). Using $\mathrm{H}_{3} \mathrm{PW}_{12} \mathrm{O}_{40}$ as the catalyst in the esterification, it presented a relative high conversion of $96.9 \%$. Nevertheless, due to its well-known strong acidity caused by the three protons in the cation position, $\mathrm{H}_{3} \mathrm{PW}_{12} \mathrm{O}_{40}$ had a lower selectivity of reaction (95.8\%) than that of $\left[\mathrm{BSPy}^{-} \mathrm{HSO}_{4}\right.$ and $[\mathrm{PVPP}-\mathrm{BS}] \mathrm{HSO}_{4}$ (entry 4). When $[\mathrm{BSPy}] \mathrm{HSO}_{4}$ was used as the catalyst, a liquid-liquid reaction system was formed. The conversion of acetic acid was $96.1 \%$ which was much higher than that of $\mathrm{H}_{2} \mathrm{SO}_{4}$ and $\mathrm{PVPP}-\mathrm{H}_{2} \mathrm{SO}_{4}$; and the selectivity of the reaction was $100 \%$, which was higher than that of $\mathrm{H}_{3} \mathrm{PW}_{12} \mathrm{O}_{40}$ (entry 5). However, [BSPy] $\mathrm{HSO}_{4}$ was easily attached onto the bottom surface of the flask reactor like a gelatinous liquid, which greatly lowered the mass transfer. When [PVPP-BS] $\mathrm{HSO}_{4}$ was used, a liquid-solid reaction system formed and a high conversion (99.6\%) and good selectivity were obtained (entry 6). Moreover, [PVPP$\mathrm{BS}] \mathrm{HSO}_{4}$ could be easily separated by vacuum filtration and reused.

Table 3 presents the comparison of the catalytic performances of [PVPP-BS] $\mathrm{HSO}_{4}$ with two reported polymer 


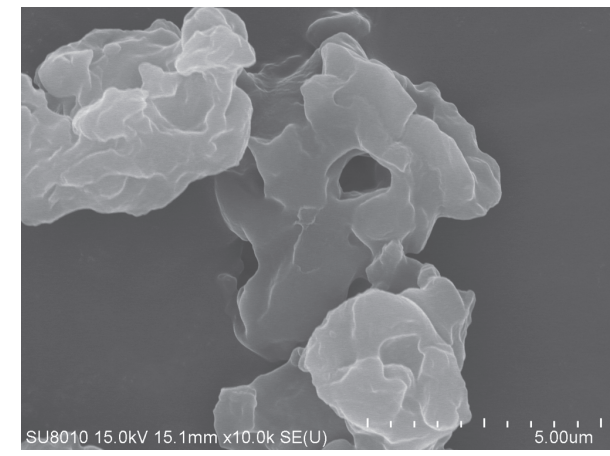

(a)

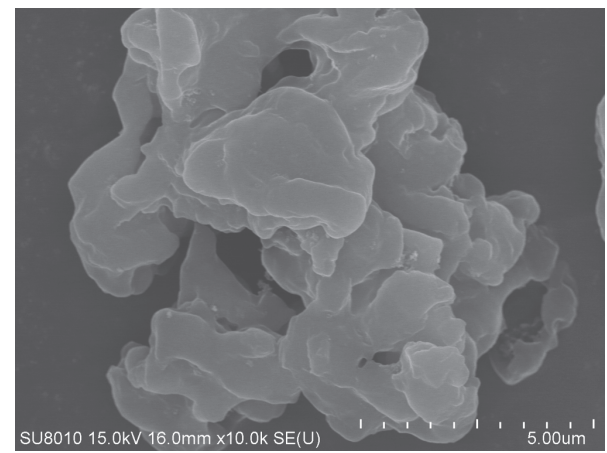

(b)

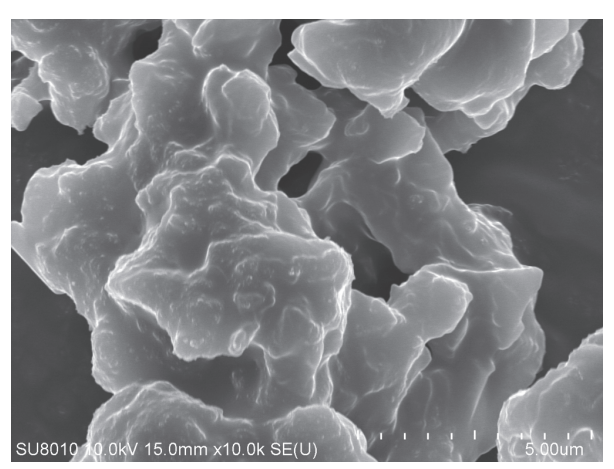

(c)

FIgURE 4: FESEM photographs of (a) PVPP, (b) PVPP-BS, and (c) [PVPP-BS] $\mathrm{HSO}_{4}$.

TABLE 3: Esterification of n-butanol and acetic acid with different polymer supported catalysts.

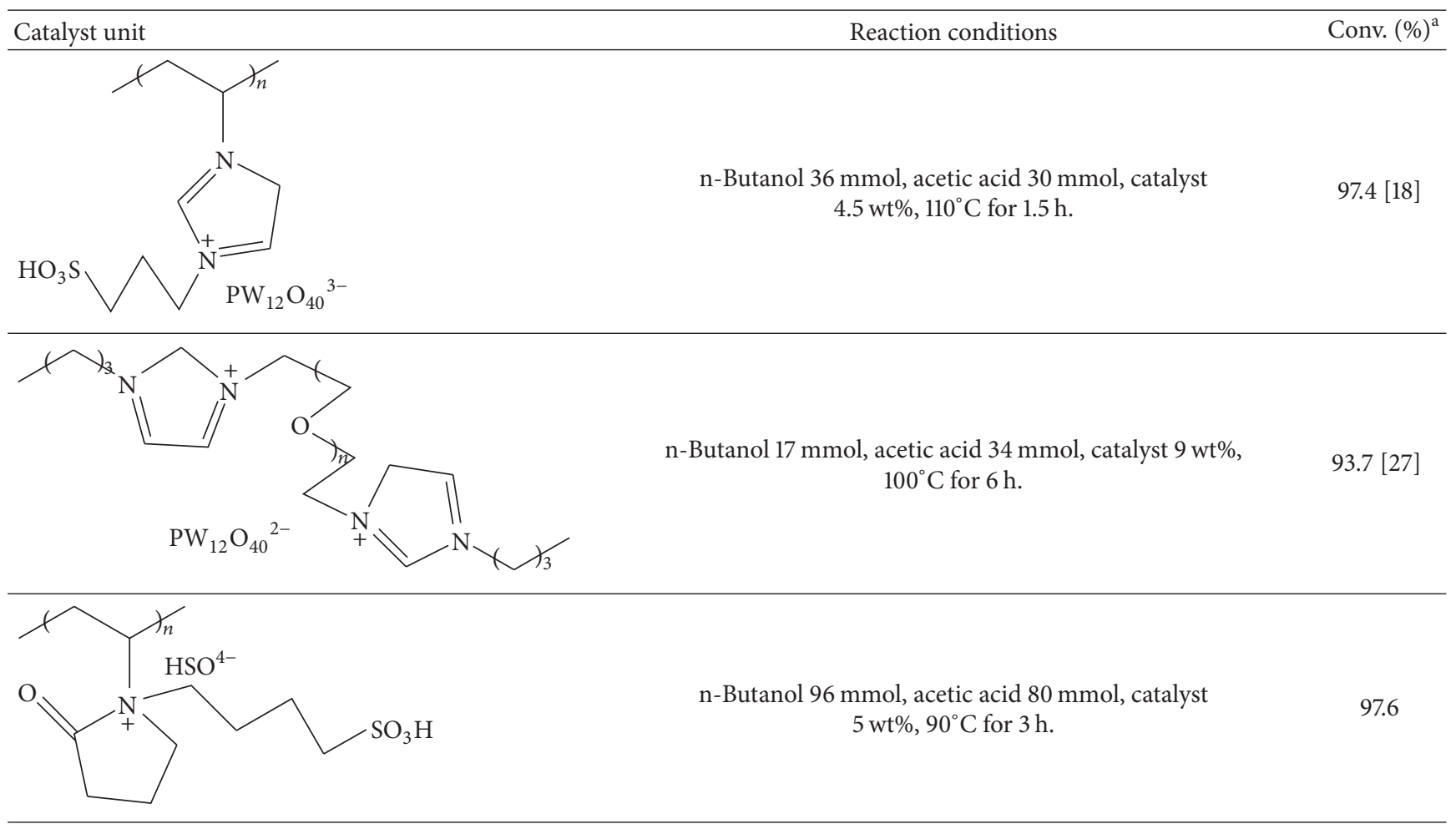

${ }^{\mathrm{a} C o n v e r s i o n}$ of acetic acid. 
TABLE 4: Esterification of different alcohols and carboxylic acids in [PVPP-BS] $\mathrm{HSO}_{4}{ }^{\mathrm{a}}$.

\begin{tabular}{|c|c|c|c|c|c|}
\hline Entry & Acids & Alcohols & Temp. $\left({ }^{\circ} \mathrm{C}\right)$ & Conv. $(\%)^{b}$ & Sel. $(\%)^{c}$ \\
\hline 1 & Acetic acid & n-Butanol & 90 & 99.6 & 100 \\
\hline 2 & Acetic acid & n-Hexanol & 92 & 99.1 & 100 \\
\hline 3 & Acetic acid & n-Octanol & 92 & 95.4 & 100 \\
\hline 4 & Propionic acid & Isobutanol & 91 & 99.3 & 100 \\
\hline 5 & n-Butyric acid & n-Butanol & 94 & 93.8 & 100 \\
\hline 6 & Oleic acid & n-Butanol & 92 & 95.6 & 100 \\
\hline 7 & Acetic acid & Benzyl alcohol & 89 & 99.1 & 100 \\
\hline 8 & Propionic acid & Benzyl alcohol & 90 & 93.2 & 100 \\
\hline
\end{tabular}

${ }^{\mathrm{a}}$ Alcohol (96 mmol); carboxylic acid ( $\left.80 \mathrm{mmol}\right)$; and [PVPP-BS] $\mathrm{HSO}_{4}$ ( $\left.8 \mathrm{wt} \%\right)$, for $3 \mathrm{~h}$.

${ }^{\mathrm{b}}$ Conversion of acetic acid.

${ }^{\mathrm{c}}$ Selectivity for ester.

supported catalysts for the esterification of acetic acid with nbutanol. It can be seen that [PVPP-BS] $\mathrm{HSO}_{4}$ exhibited similar catalytic performance as the two reported polymer supported catalysts. The conversion of acetic acid exceeded 90\%, when these polymer supported catalysts were applied in esterification of n-butanol and acetic acid. However, the difference is that the polymer supports of the reported catalysts are in the stage of laboratory while the PVPP is a commercial product. Using PVPP as catalyst support can greatly simplify the preparation process and lower production costs of the catalyst in contrast to the other two catalysts reported by Leng et al. [18] and Li et al. [27]. Therefore, [PVPP-BS] $\mathrm{HSO}_{4}$ has more potential in industrial application.

\subsection{Catalytic Activity of $[\mathrm{PVPP}-\mathrm{BS}] \mathrm{HSO}_{4}$ for Esterification} of Other Alcohols and Carboxylic Acids. In order to clarify the scope and limitations of [PVPP-BS] $\mathrm{HSO}_{4}$ catalyst for esterification, different alcohols and carboxylic acids as the reactants for esterification reactions were tested and the results are summarized in Table 4 . It can be observed that [PVPP-BS] $\mathrm{HSO}_{4}$ possessed very high catalytic activity for esterification. Excellent conversions above $90 \%$ with perfect selectivity (100\%) for corresponding esters were obtained in all investigated reactions. Moreover, the results in Table 4 demonstrate that the length of carbon chains merely affected the conversion and the selectivity (Table 4, entries 1-6). In addition, satisfactory conversions above $90 \%$ (Table 4 , entries 7,8 ) of esterification of aromatic alcohol and carboxylic acids were also obtained. Thus, all these results indicate that [PVPP-BS] $\mathrm{HSO}_{4}$ catalyst can be applied to various esterification reactions with different substrates.

3.5. Reusability of [PVPP-BS] $\mathrm{HSO}_{4}$ for Esterification. Reusability of the catalyst is one of the essential aspects for practical applications. After the reaction of each run, the solid catalyst could be recovered by filtration, dried in vacuum at $60^{\circ} \mathrm{C}$ for $2 \mathrm{~h}$. The recycling performance of [PVPP-BS] $\mathrm{HSO}_{4}$ in the esterification of acetic acid with n-butanol is illustrated in Figure 5. The conversion of the acid changed from $99.6 \%$ to $96.5 \%$ after 5 times of recycling, which indicates the high catalytic performance of [PVPP-BS] $\mathrm{HSO}_{4}$.

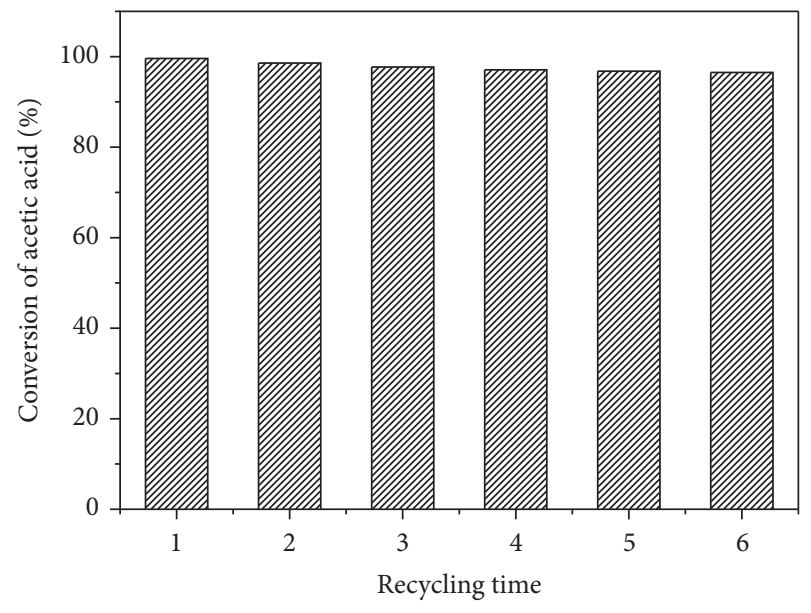

FIGURE 5: Recycling of [PVPP-BS] $\mathrm{HSO}_{4}$ in the synthesis of n-butyl acetate.

\section{Conclusions}

In conclusion, a Brønsted acidic catalyst [PVPP-BS] $\mathrm{HSO}_{4}$ was synthesized by coupling $\mathrm{SO}_{3} \mathrm{H}$-functionalized polyvinylpolypyrrolidone with $\mathrm{H}_{2} \mathrm{SO}_{4}$. This catalyst was revealed to be an efficient catalyst for various esterification reactions, presenting the advantages of practical convenience in product preparation, separation, and recovery. Moreover, the conversions for all the investigated reactions were above $90 \%$. Conversions for the reactions could still be satisfactorily maintained above $90 \%$ after the catalyst was recycled for 5 times for the synthesis of n-butyl acetate. Thus, the [PVPP$\mathrm{BS}] \mathrm{HSO}_{4}$ polymer supported catalyst, which was prepared in this study, was proved to be an efficient, reusable, and potential heterogeneous catalyst for the synthesis of carboxylic esters.

\section{Competing Interests}

The authors declare that they have no competing interests. 


\section{Acknowledgments}

The authors acknowledge the financial support of the Shenyang Science and Technology Plan Projects (no. F15-1991-12 and no. F14-231-1-28) and the Key Laboratory for Catalyst Synthesis of Polymer of the Liaoning Province (no. 2010-36), China.

\section{References}

[1] Y. Z. Zhao, J. X. Long, F. G. Deng et al., "Catalytic amounts of Brønsted acidic ionic liquids promoted esterification: study of acidity-activity relationship," Catalysis Communications, vol.10, no. 5, pp. 732-736, 2009.

[2] L. E. Hamdaoui, M. E. Moussaouiti, and S. Gmouh, "Homogeneous esterification of cellulose in the mixture N-butylpyridinium chloride/dimethylsulfoxide," International Journal of Polymer Science, vol. 2016, Article ID 1756971, 7 pages, 2016.

[3] Y. Yue, H. Liu, Y. Zhou, Z. Bai, and X. Bao, "Pure-phase zeolite beta synthesized from natural aluminosilicate minerals and its catalytic application for esterification," Applied Clay Science, vol. 126, no. 6, pp. 1-6, 2016.

[4] J. P. Pariente, I. Díaz, F. Mohino, and E. Sastre, "Selective synthesis of fatty monoglycerides by using functionalised mesoporous catalysts," Applied Catalysis A: General, vol. 254, no. 2, pp. 173188, 2003.

[5] M. Kuzminska, R. Backov, and E. M. Gaigneaux, "Selective synthesis of fatty monoglycerides by using functionalised mesoporous catalysts," Catalysis Communications, vol. 59, no. 5, pp. 222-225, 2015.

[6] F. Shi, Q. Zhang, D. Li, and Y. Deng, "Silica-gel-confined ionic liquids: a new attempt for the development of supported nanoliquid catalysis," Chemistry-A European Journal, vol. 11, no. 18, pp. 5279-5288, 2005.

[7] M. Nakajima, K. Qiao, N. Kobayashi, Q. Bao, D. Tomida, and C. Yokoyama, "Efficient dehydration of aldoximes to nitriles catalyzed by a Lewis acid ionic liquid," Chemistry Letters, vol. 40, no. 4, pp. 396-397, 2011.

[8] R.-J. Li, L. Chen, and Z.-C. Yan, "Synthesis of trimethylolpropane esters of oleic acid using a multi- $\mathrm{SO}_{3} \mathrm{H}$-functionalized ionic liquid as an efficient catalyst," Journal of the American Oil Chemists' Society, vol. 89, no. 4, pp. 705-711, 2012.

[9] E. D. Bates, R. D. Mayton, I. Ntai, and J. H. Davis Jr., " $\mathrm{CO}_{2}$ capture by a task-specific ionic liquid," Journal of the American Chemical Society, vol. 124, no. 6, pp. 926-927, 2002.

[10] A. E. Visser, J. D. Holbrey, and R. D. Rogers, "Hydrophobic ionic liquids incorporating $\mathrm{N}$-alkylisoquinolinium cations and their utilization in liquid-liquid separations," Chemical Communications, no. 23, pp. 2484-2485, 2001.

[11] J. Gui, X. Cong, D. Liu, X. Zhang, Z. Hu, and Z. Sun, "Novel Brønsted acidic ionic liquid as efficient and reusable catalyst system for esterification," Catalysis Communications, vol. 5, no. 9, pp. 473-477, 2004.

[12] S. Sahoo, P. Kumar, F. Lefebvre, and S. B. Halligudi, "Oxidative kinetic resolution of alcohols using chiral Mn-salen complex immobilized onto ionic liquid modified silica," Applied Catalysis A: General, vol. 354, no. 1-2, pp. 17-25, 2009.

[13] Y. H. Liu, L. I. Zhu, X. Q. Sun, J. Chen, and F. Luo, "Silica materials doped with bifunctional ionic liquid extractant for yttrium extraction," Industrial and Engineering Chemistry Research, vol. 48, no. 15, pp. 7308-7313, 2009.
[14] X. Z. Liang, "Novel acidic ionic liquid polymer for biodiesel synthesis from waste oils," Applied Catalysis A: General, vol. 455, no. 2, pp. 206-210, 2013.

[15] K. Handore, S. Bhavsar, A. Horne et al., "Novel green route of synthesis of $\mathrm{ZnO}$ nanoparticles by using natural biodegradable polymer and its application as a catalyst for oxidation of aldehydes," Journal of Macromolecular Science, Part A: Pure and Applied Chemistry, vol. 51, no. 12, pp. 941-947, 2014.

[16] F. Liu, L. Wang, Q. Sun, L. Zhu, X. Meng, and F.-S. Xiao, “Transesterification catalyzed by ionic liquids on superhydrophobic mesoporous polymers: heterogeneous catalysts that are faster than homogeneous catalysts," Journal of the American Chemical Society, vol. 134, no. 41, pp. 16948-16950, 2012.

[17] H. Li, Q. Zhang, and S. Yang, "Catalytic cascade dehydrationetherification of fructose into 5-ethoxymethylfurfural with $\mathrm{SO}_{3} \mathrm{H}$-functionalized polymers," International Journal of Chemical Engineering, vol. 2014, Article ID 481627, 7 pages, 2014.

[18] Y. Leng, P. Jiang, and J. Wang, "A novel Bronsted acidic heteropolyanion-based polymeric hybrid catalyst for esterification," Catalysis Communications, vol. 25, pp. 41-44, 2012.

[19] Y. Zhou, W. Kong, Y. Li, A. F. Logrieco, J. Xu, and M. Yang, "A new solid-phase extraction and HPLC method for determination of patulin in apple products and hawthorn juice in China," Journal of Separation Science, vol. 35, no. 5-6, pp. 641649, 2012.

[20] A. Kumari, G. Sarkhel, and A. Choudhury, "Effect of polyvinylpyrrolidone on separation performance of cellulose acetatepolysulfone blend membranes," Journal of Macromolecular Science, Part A: Pure and Applied Chemistry, vol. 50, no. 7, pp. 692702, 2013.

[21] M. Mokhtary and F. Najafizadeh, "Polyvinylpolypyrrolidone-

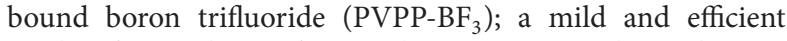
catalyst for synthesis of 4-metyl coumarins via the Pechmann reaction," Comptes Rendus Chimie, vol. 15, no. 6, pp. 530-532, 2012.

[22] L. Li, S.-T. Yu, C.-X. Xie, F.-S. Liu, and H.-J. Li, "Synthesis of glycerol triacetate using functionalized ionic liquid as catalyst," Journal of Chemical Technology and Biotechnology, vol. 84, no. 11, pp. 1649-1652, 2009.

[23] L. H. O. Pires, A. N. de Oliveira, O. V. Monteiro Jr. et al., "Esterification of a waste produced from the palm oil industry over 12-tungstophosforic acid supported on kaolin waste and mesoporous materials," Applied Catalysis B: Environmental, vol. 160-161, no. 5, pp. 122-128, 2014.

[24] K. A. Shah, J. K. Parikh, B. Z. Dholakiya, and K. C. Maheria, "Fatty acid methyl ester production from acid oil using silica sulfuric acid: process optimization and reaction kinetics," Chemical Papers, vol. 68, no. 4, pp. 472-483, 2014.

[25] G. Corro, F. Bañuelos, E. Vidal, and S. Cebada, "Measurements of surface acidity of solid catalysts for free fatty acids esterification in Jatropha curcas crude oil for biodiesel production," Fuel, vol. 115, no. 8, pp. 625-628, 2014.

[26] H. M. Fahmy, M. H. Abo-Shosha, and N. A. Ibrahim, "Finishing of cotton fabrics with poly (N-vinyl-2-pyrrolidone) to improve their performance and antibacterial properties," Carbohydrate Polymers, vol. 77, no. 4, pp. 845-850, 2009.

[27] H. Li, Y. X. Qiao, L. Hua et al., "Imidazolium polyoxometalate: an ionic liquid catalyst for esterification and oxidative esterification," Chem CatChem, vol. 2, no. 9, pp. 1165-1170, 2010. 

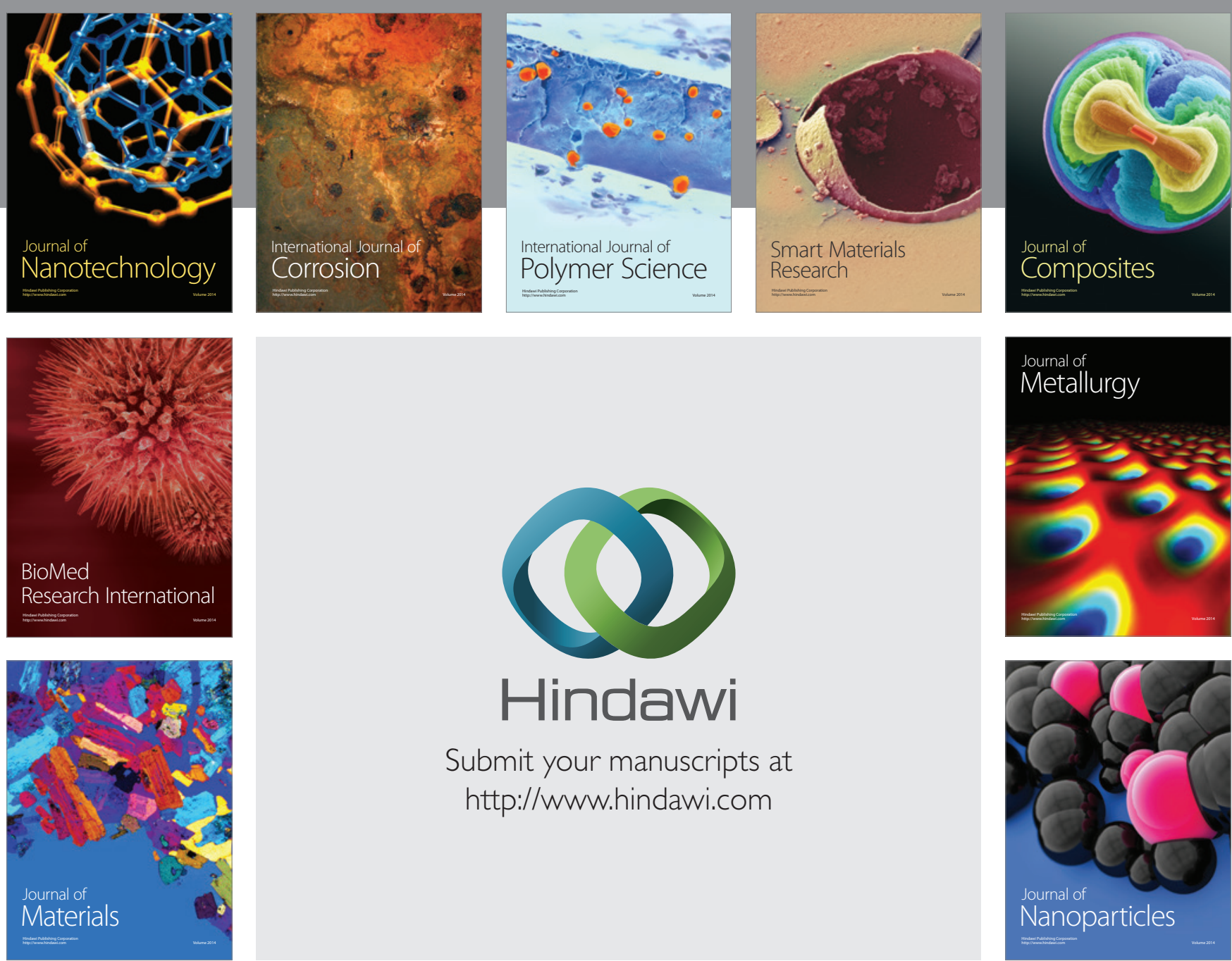

\section{Hindawi}

Submit your manuscripts at

http://www.hindawi.com

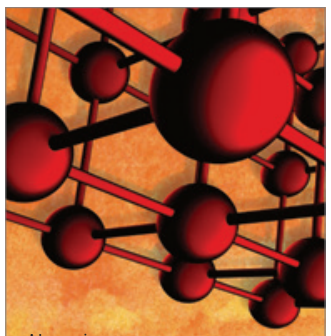

Materials Science and Engineering
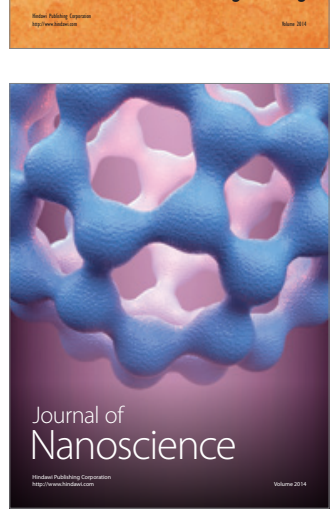
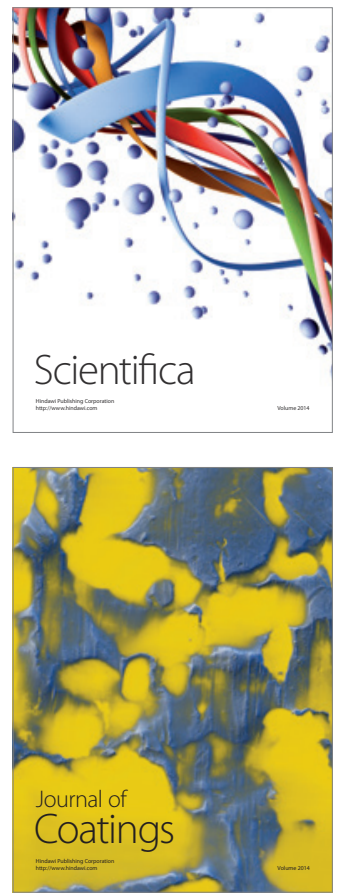
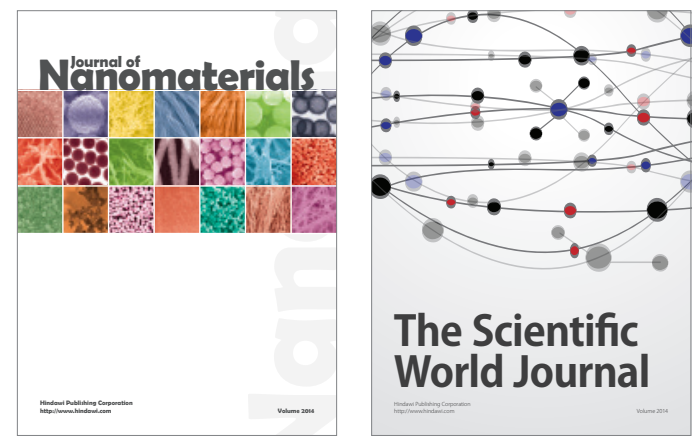

The Scientific World Journal
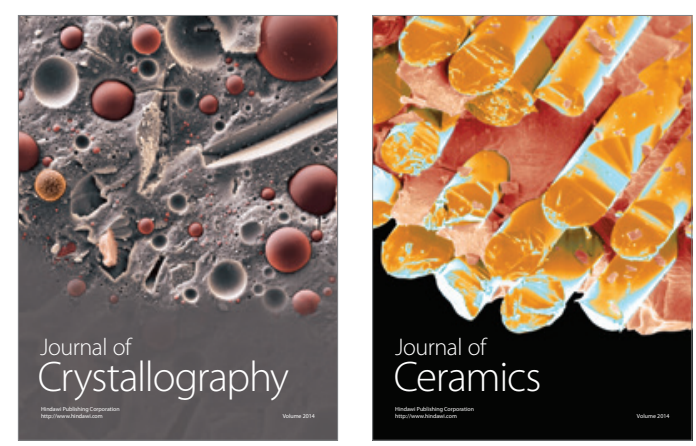
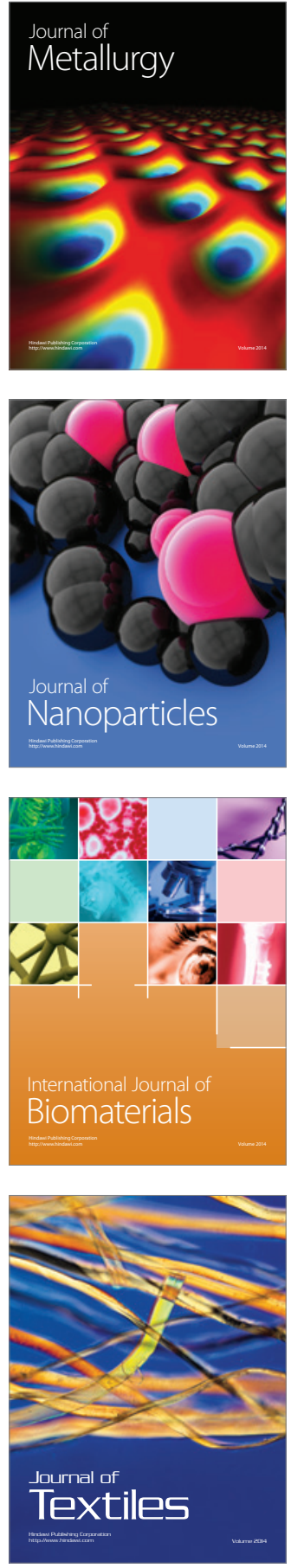